\title{
Effect of silica on the properties of cellulose acetate/polyethylene glycol membranes for reverse osmosis
}

\author{
Adnan Ahmad a,*, Sidra Waheed ${ }^{\text {a }}$, Shahzad Maqsood Khan a , Sabad e-Gul ${ }^{\text {a }}$, Muhammad Shafiq ${ }^{\text {a }}$, \\ Muhammad Farooq ${ }^{\text {b }}$, Khairuddin Sanaullah ${ }^{\mathrm{c}}$, Tahir Jamil ${ }^{\mathrm{a}}$ \\ a Department of Polymer Engineering and Technology, University of the Punjab, Quaid-e-Azam Campus, Lahore 54590, Pakistan \\ b Institute of Chemical Engineering and Technology, University of the Punjab, Quaid-e-Azam Campus, Lahore 54590, Pakistan \\ c Department of Chemical Engineering and Energy Sustainability, University Malaysia Sarawak, 94300 Kota Samarahan, Sarawak, Malaysia
}

\section{H I G H L I G H T S}

- 2-stage phase inversion protocol; involving TIPS and controlled evaporation.

- Silica is used as an additive to augment permeation performance.

- Addition of silica enhanced the fouling resistance remarkably.

- Optimum loading of silica particle is required for maximum performance.

\section{A R T I C L E I N F O}

\section{Article history:}

Received 23 July 2014

Received in revised form 2 October 2014

Accepted 6 October 2014

Available online $\mathrm{xxxx}$

\section{Keywords:}

Reverse osmosis

Polyethylene glycol

Cellulose acetate

Silica

Phase inversion

\begin{abstract}
A B S T R A C T
In this work, a series of cellulose acetate/polyethylene glycol-600 membranes, with varying ratios were prepared by 2 -stage phase inversion protocol. The permeation properties were studied by subjecting membranes in indigenously fabricated reverse osmosis plant. After optimization of different CA/PEG ratios, the membrane with highest salt rejection capacity was selected and modified with varying amount of silica. The Modified membranes were characterized for their permeation properties, hydrophilicity, compositional analysis, thermal stability, mechanical strength and morphological studies. Silica significantly influenced the permeation performance of composite membrane. The flux enhanced from 0.35 to $2.46 \mathrm{~L} / \mathrm{h} \mathrm{m}^{2}$ along with an $11.41 \%$ relative increase in salt rejection. The hydrophilicity was significantly enhanced by the addition of silica. In FTIR spectra, the broadening of the peak around $3500 \mathrm{~cm}^{-1}$ and emergence of peak at $950 \mathrm{~cm}^{-1}$ specified the incorporation of silica particles. The thermal analysis indicated the relative increase in degradation temperature $\left(\mathrm{T}_{\max }\right)$ and glass transition temperature $\left(\mathrm{T}_{\mathrm{g}}\right)$ for CPS-5 membrane. The mechanical stability of the modified membranes, increased initially, but declined with further addition of silica. The results indicated that the incorporation of $\mathrm{SiO}_{2}$ content in the casting solution improved the fouling resistance of the membranes.
\end{abstract}

(C) 2014 Elsevier B.V. All rights reserved.

\section{Introduction}

Membranes and membrane processes subsist as old as life [1-4]. Recently, synthetic membrane processes have appeared among the most innovative technologies to attain a variety of goals ranging from molecular separation to concentration of products [5]. The intrinsic characteristics of membranes like high efficiency, simplicity, selectivity, low energy consumption and good stability make membranes as an integral part of various chemical industries [6,7].

Membrane based desalination processes involve reverse osmosis (RO), electro dialysis, forward osmosis, ultrafiltration and nanofiltration $[8,9]$. The RO process was commercialized in 1970 and today it is a

\footnotetext{
* Corresponding author. Tel.: + 923216789792 (Cell).

E-mail address: adnanahmedbaloch@gmail.com (A. Ahmad).
}

leading membrane technology representing $80 \%$ of total desalination plants [10-12].

An ideal RO membrane should possess the resistance to chemical attack, excellent separation performance, good mechanical and thermal stability [13]. The performance of a membrane is notably influenced by its constituents, which affect many properties $[14,15]$. Various polymers have been used to synthesize membranes, but cellulose acetate (CA) membranes are well accepted due to their good transport characteristics, low protein adsorption, excellent water affinity, appropriate mechanical strength, excellent film-forming properties and lower cost [16,17]. However, CA has poor thermal stability, lower chemical resistance, inferior mechanical strength and vulnerable to fouling resistance. Therefore, attempts have been made to improve the performance of CA by developing hybrid organic-inorganic membranes. Few researchers have investigated the effect of alumina $\left(\mathrm{Al}_{2} \mathrm{O}_{3}\right)$, zirconia $\left(\mathrm{ZrO}_{2}\right)$, titania $\left(\mathrm{TiO}_{2}\right)$, silver 